\title{
Paternalismo estatal, autonomia e Estatuto da Pessoa com Deficiência
}

\section{State Paternalism, Autonomy and Statute of the Person with Disabilities}

\author{
Ana Lucia Pretto Pereira* \\ Flávia Balduíno Brazzale**
}

\section{Resumo}

O presente artigo busca oferecer reflexões acerca de inovações legislativas trazidas pelo Estatuto da Pessoa com Deficiência, precisamente no que diz respeito às alterações promovidas por este Estatuto no regime jurídico das capacidades civis das pessoas com deficiência. O regime jurídico das capacidades civis está diretamente relacionado a uma dinâmica entre as ideias de paternalismo e autonomia. Por essa razão, o texto começa explorando conceitos doutrinários sobre paternalismo em geral e paternalismo estatal. Em seguida, aponta definições teóricas sobre o conceito de autonomia, relacionando-as com as ideias paternalistas trabalhadas previamente. Finalmente, faz uma leitura das inovações legislativas trazidas pelo Estatuto da Pessoa com Deficiência sobre o regime jurídico de capacidades à luz dos conceitos de paternalismo estatal e autonomia, trazidos no estudo.

Palavras-chave: Paternalismo. Autonomia. Capacidade. Pessoa com deficiência.

\footnotetext{
Pós-doutora em Direito Constitucional pelo Centro Universitário Autônomo do Brasil. Mestre e Doutora em Direito Constitucional pela Universidade Federal do Paraná. Docente no Centro Universitário Autônomo do Brasil - Graduação e Mestrado. Santa Catarina - PR - Brasil. E-mail: anapereira@unibrasil.com.br.

* Mestranda em Direitos Fundamentais e Democracia no Centro Universitário Autônomo do Brasil. Docente na Universidade Sociedade Educacional de Santa Catarina. Santa Catarina - PR Brasil. E-mail: fla_brassal@hotmail.com.
} 


\section{Abstract}

This paper aims to contribute on scholar discussions about legal inovations brought by the Disabled People Act, precisely regarding the alterations on the legal regime of civil capacities for disabled people. The legal regime of capacities for disabled people is straightly related to the dynamics between the ideas of paternalism and authonomy. For this reason, the article begins exploring scholar conceptions on general paternalism and state paternalism. In the sequence, the text brings theoretical conceptions on authonomy, relating them with the previously definitions of paternalism. Finally, the text reads the legal inovations made by the Disabled People Act on the legal regime of capacities under the light of the mentioned conceptions of state paternalism and authonomy.

Keywords: Paternalism. Autonomy. Capacity. Disabled person.

\section{Introdução}

Recentemente, teve início a vigência da Lei federal n. ${ }^{0}$ 13.146/15, mais conhecida como Estatuto da Pessoa com Deficiência. Apesar de criticável sob alguns aspectos, a novel legislação tem recebido elogios, precisamente no que diz respeito à merecida atenção e proteção dispensadas às pessoas com alguma sorte de deficiência, as quais, por muito tempo, enfrentavam - e ainda enfrentam - dificuldades no que concerne à qualidade e efetividade das medidas reconhecedoras e promotoras de seus direitos fundamentais.

Por outro lado, as alterações legislativas realizadas em torno de questões relacionadas à tutela e à curatela de pessoas com deficiência, sob o argumento de promover verdadeira e efetiva proteção estatal, levantou severas problematizações quanto à real proteção que o Estatuto conseguiu trazer para a pessoa com deficiência quando, buscando promover sua autonomia, suprimiu a condição de absolutamente incapaz.

Em consequência, surge a seguinte pergunta: em razão de tais medidas - cujo objetivo se apresenta, à primeira vista, "emancipatório" -, 
teria o Estado desempenhado mal o seu papel de assegurar proteção a esses indivíduos?

Uma possível resposta compreende identificar, inicialmente, o que é e como vem a ser empregado o paternalismo estatal nos justos limites de um modelo democrático de Estado de Direito. Para tanto, o presente estudo busca trazer um breve histórico das posturas intervencionistas adotadas pelo Estado na esfera da autonomia dos indivíduos. Em seguida, será preciso apresentar qual o conceito de autonomia trabalhado no presente estudo, para, finalmente, confrontá-lo com o regime jurídico inaugurado pela Lei $n .^{\circ} 13.146 / 15$ para as pessoas com deficiência, no que diz respeito à sua capacidade para a tomada de decisões na esfera civil.

\section{Paternalismo}

Inicialmente, consigne-se que paternalismo, de acordo com a língua portuguesa, consiste em "1. Regime baseado na autoridade paterna. 2. Sistema de relação entre os chefes e os subordinados, seguindo concepção paternal da autoridade" (FERREIRA, 2010, p. 569). Tal significado permite, desde um primeiro momento, compreender que o paternalismo está atrelado à ideia segundo a qual certo sujeito, que se considera possuidor de maior conhecimento e capacidade, toma decisões em lugar de outrem, cujo bem-estar e/ou interesses se pretende resguardar.

As relações alcançadas por uma nota de paternalismo são as mais variadas possíveis. Como norte, remete-se ao cotidiano, para lembrar aquelas em que exista "alguém que se sinta capaz de proteger aquele que ele considere como sendo um necessitado, o que pode ocorrer, inclusive em detrimento da sua vontade". Aqui, leiam-se relações de âmbito privado, laboral, familiar, afetivas e, inclusive, com especial destaque para este artigo, as que envolvem o cidadão e o Estado (ROHRMANN; RÊGO, 2013, p. 119). 
Uma abordagem crítica do paternalismo tem por referência autores como Jonh Stuart Mill, Gerald Dworkin, John Rawls, Joel Feinberg, Miguel Angel Ramiro Avilés, Garzón Valdés, Marcario Alemany, Stephan Kirste, João Paulo Orsini Martinelli, Carlos Alberto Rohrmann, dentre outros. O filósofo do direito americano Gerald Dworkin, dentre alguns de seus mais importantes trabalhos ${ }^{1}$, apresenta o conceito de paternalismo nos seguintes termos: "a interferência sobre a liberdade de ação de alguém justificada por razões referentes exclusivamente ao bem-estar, benefício, felicidade, necessidades, interesses ou valores da pessoa coagida". ${ }^{2}$

É possível, portanto, concluir que paternalismo em sentido amplo significa intervenção sobre a liberdade inerente a certo indivíduo (presumidamente vulnerável frente determinada situação) sob a justificativa de promoção e proteção do seu bem-estar.

Para uma boa compreensão, o paternalismo pode ser identificado pelos seguintes caracteres, segundo João Paulo Orsini Martinelli (2010, p.106): a) interferência na esfera de liberdade de alguém por um ato comissivo ou omissivo do agente ${ }^{3}$; b) segurança sobre sua ação; c) justificativa de assegurar o bem da pessoa que sofreu a interferência ou evitar seu mal; d) presunção sobre falta de capacidade de autodeterminação do interferido; e) contrariedade à vontade do interferido.

Em continuidade, mas resultante desse paternalismo geral, encontra-se o paternalismo estatal do qual se desmembra o paternalismo judicial (ou pretoriano) e o paternalismo jurídico.

Gerald Dworkin é autor de reconhecidos artigos referente ao paternalismo, tais como: Paternalism, Paternalism: some second thoughts e Moral Paternalism.

2 Tradução de: "By paternalism I shall understand roughly the interference with a person's liberty of action justified by reasons referring exclusively to the welfare, good, happiness, needs, interests, or values of the person being coerced" (DWORKIN, 1971, p. 181).

3 "O comportamento exigido contra a vontade de alguém pode apresentar-se em três modalidades: uma informação ou um conselho; uma restrição na escolha; e a imposição de uma conduta (positiva ou negativa)" (MARTINELLI, 2010, p. 101). 
O paternalismo estatal verifica-se quando o agente que atua é o próprio Estado a favor de indivíduos que se encontrem no polo contraposto na condição de sujeitos vulneráveis e que, por tal razão, merecem a proteção do Estado por meio de mecanismos legitimamente admitidos. Consequentemente, a diferença entre o paternalismo judicial e o jurídico será determinada pelo meio que exterioriza a respectiva ação paternalista.

Nesse caminho, o paternalismo judicial é aquele exteriorizado pela atuação do Estado-juiz, ao relevar a condição de vulnerabilidade de determinados sujeitos para proferir decisões (como é o caso de um consumidor perante seu fornecedor ou do empregado perante seu empregador), garantindo, assim, maior proteção pela "crença de que estes estariam sempre em desvantagem nas várias relações travadas no seu dia a dia" (ROHRMANN; RÊGO, 2013, p.127)4.

Já o paternalismo jurídico é aquele cuja proteção estatal se exterioriza por meio das normas jurídicas devidamente emanadas pelo Estado (ROHRMANN; RÊGO, 2013, p.127)5. Objetivamente, Ramiro Avilés conceitua o paternalismo jurídico como sendo "a intervenção do Estado sobre o comportamento das pessoas mediante o estabelecimento

4 Pode-se pensar na hipótese de determinação da inversão do ônus da prova em prol daquele consumidor que, munido da verossimilhança de suas alegações ou de sua hipossuficiência, fica isento da responsabilidade de produção de provas técnicas confirmatórias de que o produto que Ihe causou danos físicos ao ser utilizado já saiu de fábrica apresentando riscos ao usuário. Nesta hipótese, o legítimo reconhecimento da vulnerabilidade fática deste consumidor demonstra a incidência do paternalismo judicial ou pretoriano.

5 Em se tratando de relações materialmente desiguais, a exemplo das relações de consumo, Daniel Sarmento manifesta seu particular entendimento sobre a não identificação do paternalismo nas normas de ordem pública que regulamentarão tais questões. A saber: "Quando o direito positivo intervém nessas relações materialmente desiguais, ditando normas de ordem pública em proveito da parte hipossuficiente, ele não está, a rigor, desconsiderando a sua autonomia privada como agente moral. E não se trata de paternalismo, ao contrário do que os críticos à direita insistem em apregoar, mas de proteção da própria liberdade, cuja interpretação tem de se articular com o valor igualdade, numa ordem jurídica que se preocupa igualmente com ambos" (SARMENTO, 2006, p. 158). 
de normas jurídicas ou desenvolvimento de políticas públicas que aconselham, desencorajam, impeçam ou criminalizam sua realização". 67

Desta feita, experimenta-se paternalismo jurídico quando o Estado, ao assumir a posição de garantidor da ordem pública por meio de seus legítimos poderes, expede normas impositivas e restritivas de liberdade, independente do consentimento de seus destinatários, tendo como objetivo o bem-estar coletivo e uma pacífica convivência social. Ainda é possível que tais medidas se concretizem sobre um indivíduo, de modo que se encontre protegido dele próprio. ${ }^{8} 9$

Por outro lado, é importante observar que o Estado age de modo paternalista em virtude, sobretudo, do empoderamento que Ihe é conferido na condição de Estado de Direito legítimo. Ao Estado incumbe atingir os objetivos fundamentais de garantia e preservação do pluralismo e tutela da dignidade da pessoa humana.

Nesse sentido, sintetiza Macario Alemany (2005, p. 265): "se o paternalismo geral consiste no exercício de um poder, o paternalismo jurídico consistirá no exercício de um poder jurídico". Em princípio, as (boas) razões que fundamentam referida atuação estatal de modo impositivo se traduzirão como meio necessário para evitar danos físicos, psíquicos ou econômicos sobre o beneficiado (VALDÉS, 2016, p.156).

6 Tradução livre: "El paternalismo jurídico supone, em primer lugar, la intervencíon del Estado sobre el comportamento de las personas mediante el establecimiento de normas jurídicas o el desarrollo de políticas públicas que aconsejam, desalientam, obstaculizan o criminalizan su realización" (RAMIRO AVILÉS, 2006, p. 221).

7 Dworkin (1971, p. 181-188) exemplifica a interferência paternalista a partir de algumas situações fáticas, como: leis que proíbam as pessoas de nadar em praia pública quando o guarda-vidas não estiver presente, leis que exigem uma licença para exercício de profissões sob pena de multa e prisão para os que se envolverem em alguma prática, leis que regulam as taxas de juro máximo para empréstimo ou leis que proíbam diversas formas de jogos de azar, dentre outras.

8 Sobre esse assunto, verifica-se o Art. 13 do Código Civil: "Salvo por exigência médica, é defeso o ato de disposição do próprio corpo, quando importar diminuição permanente da integridade física, ou contrariar os bons costumes. Parágrafo único. O ato previsto neste artigo será admitido para fins de transplante, na forma estabelecida em lei especial".

9 Interessante se faz diferenciar a figura comumente citada pela doutrina sob a denominação de autopaternalismo. A hipótese de autopaternalismo ocorrerá "quando alguém solicita a privação de sua própria liberdade para evitar prejuízos. [...] Exemplo comum é o dependente químico pedir para ser amarrado quando não houver alguém por perto que o impeça de usar drogas [...]". (MARTINELLI, 2010, p.108). 
Por outro lado, entre a conceituação de paternalismo justificado e injustificado, doutrinas antipaternalistas repudiam a imposição coercitiva de ações como base válida para perseguição do bem-estar de alguém. Tal doutrina discorre sobre o risco da atitude paternalista implicar a desconsideração de certos direitos humanos ou conferir à pessoa incapaz a posição de objeto merecedor da benevolência estatal (RAMIRO ALVILÉS, 2006, p. 215-217).

Nesse caminho, cabe fazer uma breve observação. Existe uma linha muito tênue entre o paternalismo e o autoritarismo. O paternalismo excessivo e desproporcional pode levar ao comprometimento da autonomia individual quando atuar impositivamente em detrimento dos princípios fundacionais do Estado Democrático de Direito. Em contrapartida, o paternalismo aplicável por meio dos limites justos e equilibrados é benéfico e indispensável em situações necessárias de especial proteção.

Portanto, não obstante ser necessário preservar certo olhar crítico sobre o paternalismo, o próprio fato de se experimentar, na prática, certos desequilíbrios sociais, já é o suficiente por reclamar a presença de certas medidas paternalistas ${ }^{10}$.

Também Dworkin (1971), associado ao pensamento de Stuart Mill, reconhece a necessidade de intervenção paternalista estatal em situações que minimamente o exija, e as quais, para além de se ocuparem com a felicidade e o bem-estar do indivíduo, promovam a proteção e não violação à sua autonomia e liberdade ${ }^{11}$.

10 Nos dizeres de Ernesto Garzón Valdés (2016, p. 155-173), "siempre hay uma buena razón a favor de una prohibición o de um mandato jurídico".

11 "Em geral, os casos mais fáceis de lidar são aqueles que podem ser discutido nos termos que Mill pensava ser tão importante - uma preocupação não só pela felicidade ou bem-estar, em algum sentido amplo, do indivíduo, mas sim uma preocupação com a autonomia e liberdade da pessoa". Tradução livre de: "In general, the easiest cases to handle are those which can be argued about in the terms which Mill thought to be so important - a concern not just for the happiness or welfare, in some broad sense, of the individual but rather a concern for the autonomy and freedom of the person". (DWORKIN, 1971, p. 188). 
Há de seobservarque esta intervenção pode serdirigida diretamente ao indivíduo para quem o tratamento paternalista é destinado (como no caso das leis que exigem o uso do cinto de segurança em veículos automotores $)^{12}$, ou ainda ser direcionada a outrem para que venha, a posteriori, resultar na produção de efeitos em prol do sujeito eleito (como são as exigências legais para que locais privados e públicos cumpram com a reserva de espaços livres e assentos próximos a corredores e com boa visibilidade enquanto meio de efetivação do direito à cultura das pessoas com deficiência) ${ }^{13}$. Tal diferenciação é representada pela classificação que distingue paternalismo puro (ou direto) e paternalismo impuro (ou indireto), a saber:

Em 'puro' quando a classe de pessoas cuja liberdade restrita for idêntica à classe de pessoas cujo benefício se destina [...]. No caso do paternalismo 'impuro', a tentativa para proteger o bem-estar de uma classe de pessoas vai envolver, restringir a liberdade de outras pessoas além daquelas que são beneficiadas ${ }^{14}$.

Outra importante classificação que permite compreender o paternalismo jurídico em termos mais detalhados está entre paternalismo rígido (ou hard) e paternalismo moderado (ou soft), cujo fator diferenciador será o grau de discernimento do beneficiado.

12 Art. 65 - Lei n 9.503/97 (Código de Trânsito Brasileiro): "É obrigatório o uso do cinto de segurança para condutor e passageiros em todas as vias do território nacional, salvo em situações regulamentadas pelo CONTRAN".

13 Art. 44 - Lei $n^{\circ}$ 13.146/2015 (Estatuto da Pessoa com Deficiência): "Nos teatros, cinemas, auditórios, estádios, ginásios de esporte, locais de espetáculos e de conferências e similares, serão reservados espaços livres e assentos para a pessoa com deficiência, de acordo com a capacidade de lotação da edificação, observado o disposto em regulamento. $\S 1^{\circ}$ Os espaços e assentos a que se refere este artigo devem ser distribuídos pelo recinto em locais diversos, de boa visibilidade, em todos os setores, próximos aos corredores, devidamente sinalizados, evitando-se áreas segregadas de público e obstrução das saídas, em conformidade com as normas de acessibilidade. [...]".

14 Tradução livre de: "Thus we may first divide paternalistic interferences into 'pure' and 'impure' cases. In 'pure' paternalism the class of persons whose freedom is restricted is identical with the class of persons whose benefit is intended to be promoted by such restrictions. [...] In the case of 'impure' paternalism in trying to protect the welfare of a class of persons we find that the only way to do so will envolve restricting the freedom of other persons besides those who are benefitted". (DWORKIN, 1971, p. 183). 
Desta feita, paternalismo rígido é aquele exercido como modo de intervenção em favor de um indivíduo que, gozando de suas plenas faculdades mentais, submete seu bem-estar ao risco de situação gravosa (pode-se pensar na advertência que um motorista devidamente capacitado e habilitado recebe de um policial impedindo-lhe de trafegar por certa estrada passível de deslizamentos) $)^{15}$. Contrariamente, o paternalismo moderado trata da hipótese quando a intervenção se efetivar em prol de indivíduo que não esteja ou não possua pleno gozo de suas faculdades mentais para coerente compreensão dos fatos (é o caso de intervenção sobre a conduta comissiva ou omissiva de uma criança, doentes mentais ou adultos com perturbações mentais temporárias) (MARTINELLI, 2010, p. 115).

Com base em tais compreensões, é possível, preliminarmente, concluir que o paternalismo sempre consistirá na intervenção para salvaguardar um bem a certo indivíduo, podendo vir a ser exercido nos mais variados âmbitos e pelos mais variados sujeitos.

Aquele que cumpre a atitude paternalista poderá realizá-la por insistente esclarecimento dos riscos a que o beneficiado se expõe (desestimulando-o para a prática do ato), ou ainda atuar de modo mais veemente pela imposição de sanções ao beneficiado ou a terceiros.

Isso posto, duas considerações a fazer: o paternalismo, de uma forma ou de outra, sempre implicará no comprometimento da liberdade do beneficiado (afinal, se o mesmo já atuasse na conduta almejada, uma conduta paternalista não se faria necessária); e, segundo, o beneficiado só é assim denominado por ser considerado alguém que, aos olhos daquele que age paternalisticamente, é sujeito vulnerável e imprescindivelmente conclama por amparo em razão de "não possuir autonomia para o ato" (MARTINELLI, 2010, p.120).

Não há dúvidas quanto à possibilidade de o Estado adotar condutas paternalistas, sendo certo que as discussões se acaloram sobre os

15 Nesse sentido, Ana Ferraz Caldas (2002, online) discorre: "Efetivamente, parece que o paternalismo forte intervém na esfera de ação de sujeitos que sabe competentes, mas que julga dotados de menor competência que o Estado". 
limites e meios de atuação. Nesse caminho, uma compreensão sobre a forma pela qual o Estado se confrontou historicamente com a liberdade de seus indivíduos impulsionará o entendimento sobre o modo pelo qual este Estado de Direito, hoje, ao reconhecer o pluralismo existente no seio da sociedade, atua paternalisticamente para "promover" ou "impedir" a autonomia de determinados grupos de indivíduos.

\subsection{0 paternalismo estatal}

Uma compreensão sobre as atitudes paternalistas do Estado e, consequentemente, sobre o modo de reconhecimento da liberdade e autonomia atribuídas aos seus indivíduos, está relacionada com as fases históricas vivenciadas até a caracterização do Estado em sua estrutura atual. Aderson de Menezes (1998) atenta para a impossibilidade de classificação cronológica dos tipos de Estado. Referido autor ressalta que os tipos estatais podem, inclusive, conter características semelhantes embora constituídos em diferentes épocas, "porque, na verdade, e os acontecimentos o comprovam fartamente, um tipo estatal contemporâneo ou a ser estruturado e posto em funcionamento pode ser semelhante a outro já conhecido na antiguidade"16. Um olhar sobre o processo de construção dos institutos é fundamental para o entendimento de como o conceito de Estado, naquilo que concerne à sua posição de garantidor da liberdade individual, foi sendo moldado de modo a repercutir na esfera privada individual, ao expressar uma maior ou menor interferência estatal.

No contexto do Período Medieval ${ }^{17}$, o ideário de liberdade estava adstrito à concepção de pertencimento a um grupo o que, por consequência, prejudicava o reconhecimento de sujeitos em sua

\footnotetext{
16 Aderson de Menezes (1998, p. 105-106) ainda complementa ao dizer que "o subsídio histórico demonstra, não raras vezes, que quase nada constitui novidade em cima da terra, pois debaixo do sol quase tudo se repete, até mesmo em ciclos, reversíveis e irreversíveis, que ligam fatos entre si e unificam o desenvolvimento social".

17 De acordo com Carvalho (2008, p. 80), "o período medieval vai desde a queda do Império Romano do Ocidente (395), ou a queda do Império Romano do Oriente (476), até a tomada de Constantinopla pelos turcos (1453), ou o descobrimento da América (1492)".
} 
individualidade. Referido período histórico pode ser identificado a partir de três características principais: "o cristianismo, as invasões dos bárbaros e o feudalismo" (DALLARI, 2012, p. 74).

Aponta-se que a concepção religiosa buscava reunir todos os cristãos em uma só unidade que pudesse concretizar o "Império da Cristandade", dentro do qual o não reconhecimento da diversidade de seus membros contribuiria para atenuar qualquer ameaça à ordem posta. Paralelamente, as invasões bárbaras e as organizações feudais também descentralizaram a existência de um só poder governante, vindo a contribuir para a formação de um cenário fragmentado na existência de diversos poderes menores, com caráter normativo.

Esse cenário impôs fragilidade ao próprio direito, por nele minimizar os critérios de racionalidade, calculabilidade e previsibilidade (PINHEIRO, 2015, p.104), levando a burguesia a buscar a instauração de uma nova ordem jurídica, permeada por uma revolução que traçaria as bases do consequente Estado Liberal. Para Rosalice Fidalgo Pinheiro (2015, p. 104), "com a função histórica de resgatar a unidade política e social fragmentada em poderes locais, transitou-se para a concentração de poder, atribuído a um ente abstrato e impessoal: o Estado Moderno".

Com a Idade Moderna, consegue-se instituir um novo paradigma sobre a compreensão de liberdade, igualdade e propriedade ${ }^{18}$. De acordo com Adriana Schier (2002, p. 37), a perspectiva liberalista, que surge com a queda do absolutismo, inaugura uma nova compreensão, segundo a qual "o homem passa a ser visto como sujeito capaz de construir sua história, determinando seu futuro a partir da razão"19.

18 Ressalta-se que as mudanças ocorridas na idade moderna, conforme Adriana Schier (2002, p. 3637 ), foram após determinado momento onde, o Estado absoluto, representado pelo rei, perde seu poder para as lutas sociais, políticas, jurídicas, econômicas e mesmo filosóficas que inauguram um canal de libertação por meio dos princípios liberais.

19 John Locke e Jacques Rousseau foram expoentes que assentaram as bases da teoria contratualista nesta concepção. Rousseau justifica a legitimidade do poder estatal, por meio da teoria do contrato social, como forma socialmente instituída para criação e manutenção de um território pacífico que garantisse segurança e o exercício dos direitos naturalmente pertencentes ao homem. Ainda, Daniel Sarmento (2006, p.7) discorre sobre o entendimento de J.Jacques Rousseau ao dizer que no seu contrato social, os indivíduos alienavam toda sua liberdade para um corpo social a qual todos pertenciam e deste modo, favoreceria um absolutismo das maiorias, que poderia atropelar os direitos das minorias. 
Pelo entendimento de que o homem gozava de direitos que Ihes eram inatos, conferidos anteriormente à própria concepção de Estado, buscou-se garantir a concepção de um Estado minimamente intervencionista, assegurando a proteção aos direitos e à liberdade individual. Nos dizeres de Jorge Reis Novais (1987, p.101),

o que distingue o Estado de Direito liberal dos tipos históricos anteriores, nomeadamente do Estado absoluto, não é tanto uma diferente estruturação e organização dos poderes, quanto o assumir da defesa e garantia dos direitos naturais do homem como fim primordial do Estado.

No período da modernidade, não se concebe a ação ou legitimidade de qualquer conduta paternalista estatal. Ao contrário, o distanciamento imposto ao Estado sobre a vida privada de seus indivíduos busca fomentar a própria autonomia da vontade pelo exercício da liberdade contratual.

Para os liberalistas, o homem se reconhece e pode ser representado pelo seu patrimônio, de modo que a liberdade desse período distanciase do ser para se enraizar na capacidade de "participar de relações jurídicas patrimoniais sem interferência do Estado, configurando-se uma tutela negativa". (TEIXEIRA, 2010, p. 127).

É em virtude do valor atribuído à propriedade nesse período que a proteção conferida à autonomia do indivíduo centra-se propriamente na proteção do patrimônio, chegando-se à conclusão de que os ideais de liberdade e igualdade restariam consagrados apenas no campo formal, restringindo-se, sobremaneira, a proteção estatal da autonomia à figura do cidadão burguês (FARIAS; ROSENVALD, 2011, p. 2).

Em tal esteira, o individualismo exacerbado do Estado liberal levou a efeitos inevitáveis: monopólios, exclusões sociais, exploração do trabalhador, ausência de atendimento básico, desigualdade e outras incontáveis demandas sociais. Tal cenário possibilita a conclusão de que o modelo do Estado liberal traria sérios prejuízos ao que concebemos hoje como dignidade da pessoa humana. 
Das mazelas criadas pela ausência estatal surge, permeado por clamores, lutas e reivindicações sociais, um Estado intervencionista que toma para si as atribuições necessárias em prol da concepção de uma sociedade mais igualitária, e de um Estado que busca dar efetividade aos direitos fundamentais e sociais. Trata-se do denominado Estado Social (Sozialstaat) ${ }^{20}$.

É no século $X X$ que o Estado social se define permeado pelos reflexos gerados no primeiro pós-guerra e pela necessidade de reestruturar sua atuação perante uma sociedade massificadora, cuja desigualdade se instaurava face ao poderio atrelado às mãos de poucos. A superioridade resgatada pelo Estado, colocando-o como interveniente soberano pela promoção dos direitos individuais (como os direitos do trabalho, da educação, da previdência), fomentador econômico e ente responsável pelo amparo e inclusão social das minorias, é o que traduz o novo ethos político desse marco histórico (BONAVIDES, 2013, p. 184).

Porém o modelo paternalista e monopolizador do Estado social criou uma realidade de incontáveis atribuições sociais que se mostraram de difícil cumprimento. (ROHRMANN; RÊGO, 2013, p. 125). Percalços, como a incapacidade de atuação, globalização econômica e a insuficiência de recursos financeiros, resultaram em uma verdadeira crise no século $X X$.

Muitas das dificuldades do Estado Social começam a ser superadas a partir de novas ideologias, como a neoliberal. De qualquer modo, a política paternalista ainda permanece. Hoje, porém, "percebe-se, sobretudo nos países da América Latina, que os governos encontraram na política paternalista uma forma de não incorrer nos

20 Chama-se atenção ao fato de que "não se pode confundir o Estado Social com o modelo Assistencial ou de Providência (welfare state) porque ambos têm seu núcleo de preocupação direcionado à consecução do bem-estar dos cidadãos e o seu acesso a um mínimo progressivamente elevado de bens materiais. Tais modelos relevam as prestações do Estado como forma de minorar as situações de miséria dos indivíduos, assegurando-se a todos um mínimo de subsistência vital. Contudo, não têm qualquer preocupação em garantir a intervenção da sociedade civil na esfera do poder público" (SCHIER, 2002, p. 69). 
erros do Estado Social e ao mesmo tempo ter ao seu lado a aprovação popular" (ROHRMANN; RÊGO, 2013, p. 125).

No cenário brasileiro, identifica-se o emprego de posturas paternalistas, as quais, criticáveis ou não, deverão obediência aos termos constitucionais como pressuposto básico de legitimidade. Afinal, foi somente com a Constituição de 1988 - oportunamente denominada como Constituição Cidadã - que as garantias e liberdades individuais ganharam uma renovada nota de fundamentalidade.

Tutelada como direito fundamental, "a liberdade, que ora denominamos autonomia privada, recebeu tutela positiva." (TEIXEIRA, 2010, p.128). Em outras palavras, o Estado passa a ser o garantidor do respeito e proteção desse direito por meio de normas jurídicas e/ou ações específicas, visando concretizar a igualdade material.

Conforme observa Ana Carolina Brochado Teixeira (2010, p.102), a busca pelo equilíbrio necessário ao Estado contemporâneo impõe respeito às particularidades individuais. Logo, a interferência estatal que se transmutou de mínima para máxima, do Estado liberal ao social, deve ser hoje "racional para que a interferência limitadora exista apenas quando necessária, de modo que, no âmbito de um direito civil-constitucional, a ingerência externa apenas ocorra quando a ação humana invade a esfera jurídica de terceiros ou quando há vulnerabilidade".

Desta feita, o reconhecimento da liberdade e proteção da autonomia individual como direito inerente aos indivíduos é fruto de uma conquista paulatina que foi permeada por muita luta social, sendo, porém, decisiva para formação de um Estado Democrático de Direito sustentado por pilares que promovem os direitos humanos e fundamentais dos cidadãos por meio de uma atuação estatal justa e equilibrada. Referida atuação estatal, tendo a dignidade humana enquanto fim último, preserva a autonomia dos indivíduos, dentro de limites que restrinjam, embora não suprimam, liberdades.

A presença do Estado na esfera de liberdade individual é determinante para fins de identificação do âmbito de proteção da 
autonomia da vontade. Nesse sentido, delimitar os contornos do que venha a ser "autonomia" permitirá esboçar os limites permissivos para o paternalismo estatal, especialmente em se tratando de sujeito que possa se encontrar, ainda que transitoriamente, em situação de vulnerabilidade, como pode ser o caso da pessoa com deficiência ${ }^{21}$.

\section{Autonomia}

Inicialmente, observe-se que o conceito de autonomia contrapõese ao conceito de heteronomia. Heteronomia remete a submissão e obediência a uma lei exterior ou à vontade de alguém, ao passo que autonomia caracteriza-se pela faculdade de governar a si mesmo por suas próprias escolhas, com independência (CABRAL, 2004, p. 85).

Assim, a autonomia pode ser representada na liberdade que 0 sujeito possui de autodeterminar-se, de modo que sejam suas próprias vontades que the movam pela busca daquilo que sua consciência julgar como melhor para si. É por essa razão que a independência que caracteriza o indivíduo autônomo está também refletida na noção de autogoverno, que significa atuar "livremente e sem interferências [...], seja pela força da coerção, a persuasão, o paternalismo ou a manipulação" (MARTINELLOI, 2010, p. 167).

Autonomia, porém, não significa absoluta indiferença a interferências externas que recomendem certas atitudes. Um indivíduo pode deixar de praticar qualquer conduta que esteja sendo realizada, mas, sempre que o fizer, fará não por obrigação ou imposição, e sim porque

21 A Convenção Internacional sobre os Direitos das Pessoas com Deficiência, promulgada pelo Decreto $n .^{\circ}$ 6.949/09, assim como o Estatuto da Pessoa com Deficiência, imprime à deficiência dos indivíduos o caráter de longo prazo, silenciando quanto a ser permanente ou não (cf. art. $1 .^{\circ}$ da Convenção, reproduzido no art. $2 .^{\circ}$ do Estatuto). Por outro lado, o Decreto n. ${ }^{\circ} 3.298 / 99$, que regulamenta a Lei n. ${ }^{\circ} 7.853 / 89$ (Política Nacional para Integração da Pessoa com Deficiência), prevê que a deficiência pode ser transitória ou permanente. Todos esses atos legislativos (ao lado de outros, sobre o mesmo tema) encontram-se em vigor. Diante desse quadro, à primeira vista observa-se, no campo do direito positivo, possibilidade da deficiência ser considerada de longo prazo, transitória ou permanente. Um estudo sobre a aplicabilidade do Estatuto pode permitir uma delimitação conceitual mais precisa; a medida, porém, escapa aos objetivos do presente artigo. 
houve a modificação de sua vontade (MARTINELLOI, 2010, p. 168). Por exemplo, ainda que haja inúmeras campanhas de conscientização para a prática de hábitos saudáveis, o indivíduo autônomo tão somente deixará a ociosidade de lado quando o seu próprio querer lhe impulsionar na criação de uma nova rotina.

Stephan Kirste (2013, p. 74) discorre, primeiramente, sobre a compreensão da autonomia pela variante liberal ao dizer que esta só reconhecerá uma decisão legitimamente autônoma "se estiver investida de uma medida mínima de racionalidade." Logo, referida exteriorização pressupõe o pleno gozo das faculdades mentais, bem como ciência das informações adequadas para fundamentar a decisão proferida. Diversamente, para uma variante comunitarista, uma vez cumpridas as condições de racionalidade, referida decisão deverá estar em consonância com valores comunitários vigentes (KIRSTE, 2013, p. 75).

Conclui-se que a verdadeira autonomia é formada pela soma de três elementos primordiais, quais sejam: capacidade de autodeterminação, informações e vontade ${ }^{22}$. De todo modo, embora algumas intervenções estatais no âmbito da autonomia individual (através de políticas públicas ou normas jurídicas) possam ser imprescindíveis para manutenção da ordem social e garantia do bem-estar individual, o "critério para a precisão, crítica ou garantia do paternalismo é a autonomia." (KIRSTE, 2013, p. 74).

Bem pondera Ana Ferraz Caldas (2012, p. 67) ao discorrer que "verdadeiramente, o princípio da autonomia não pode ser tomado de forma tão extrema que impossibilite qualquer intervenção paternalista, pois no limite restringiria a própria intervenção sobre os menores ou a baseada no princípio do dano a terceiros".

22 Nos dizeres de Stephan Kirste (2013, p. 75): "Primeiro, uma verdadeira autonomia é, de fato, impossível sem uma medida mínima de capacidade para autodeterminação. Segundo, aqui não deve ser controvertido o fato de que a autonomia é composta de um componente racional e de um componente volitivo". 
Por tudo isso, o respeito à autonomia é que dimensionará a legitimidade das intervenções paternalistas para que nada se imponha de forma desmedida a levar o comprometimento injustificado da liberdade individual. Por fim, e ainda dentro da conceituação de autonomia, vale abrir parênteses para uma breve consideração sobre o emprego das variações terminológicas existentes entre autonomia da vontade e autonomia privada.

Embora parte da doutrina refira-se a ambos os termos de forma sinônima, há diferenças pontuais. A autonomia da vontade deve ser compreendida como o impulso que parte do foro íntimo do sujeito, ligando-se à vontade real ou psicológica em decorrência do exercício de sua própria liberdade de se autodeterminar.

A primeira influência importante para o princípio da autonomia da vontade está na ética fundada por Kant, segundo a qual o valor supremo estaria no próprio homem e, por esse motivo, o impediria de se submeter a qualquer outra lei que não aquelas criadas para si mesmo (PINHEIRO, 2002, p. 392). A segunda influência que pode ser descrita é a do modelo liberal de ordenação estatal, em razão do amplo poder da vontade conferido aos indivíduos para decidirem autonomamente sobre as questões patrimoniais, considerando que toda intervenção do Estado deveria ser minimizada na maior medida possível (TEIXEIRA, 2010, p. 129).

Já a autonomia privada distancia-se desse ato volitivo subjetivo que a autonomia da vontade expressa para se relacionar ao conceito de "negócio jurídico". Érico Cabral (2004, p. 93) conceitua autonomia privada como "um poder reconhecido pelo ordenamento jurídico aos particulares para que estabeleçam regras próprias para melhor otimizar suas atividades". De acordo com Daniel Sarmento, autonomia privada em sentido amplo "é entendida como a capacidade do sujeito de direito de determinar seu próprio comportamento individual" (SARMENTO, 2006, p. 150).

Nessa toada, a autonomia privada diz respeito a um direito objetivo consistente no reconhecimento dado pelo ordenamento jurídico 
ao particular para auto-regulamentação de suas relações privadas nos limites legais. Com as devidas observações, a compreensão de autonomia sempre irá pressupor o exercício da liberdade intrínseca a todo ser humano responsável pelo exercício de suas próprias escolhas, realizadas por meio de qualquer forma de expressão.

Logo, se "livres devem ser os homens e as mulheres, para realizarem seus projetos de vida, e não o Estado," (SARMENTO, 2006, p. 150) como ficará a situação daquele indivíduo que, por qualquer circunstância, temporária ou permanente, encontrar-se incapacitado para o exercício de sua autonomia? Como vem sendo assegurada a liberdade da pessoa com deficiência?

O Estatuto da Pessoa com Deficiência reproduz o modelo social adotado na Convenção Internacional das Pessoas com Deficiência. Por modelo social pode-se entender a dimensão socializante que referido Estatuto imprime ao regime jurídico aplicável às pessoas com deficiência no país. O Estatuto define, nos mesmos termos da Convenção, a pessoa com deficiência da seguinte maneira:

Considera-se pessoa com deficiência aquela que tem impedimento de longo prazo de natureza física, mental, intelectual ou sensorial, o qual, em interação com uma ou mais barreiras, pode obstruir sua participação plena e efetiva na sociedade em igualdade de condições com as demais pessoas. (Grifou-se).

Pode-se observar que há, aqui, um verdadeiro giro no que diz respeito à compreensão da ideia de deficiência, a qual passa a estar relacionada mais a fatores externos do que às limitações funcionais dos indivíduos. Quando o Estatuto, da mesma maneira que a Convenção, agrega, ao conceito de deficiência a interação da pessoa com o meio, está a sugerir que quanto maior a acessibilidade da pessoa a meios de participação na sociedade em que se insere, menor será a possibilidade de se sentir e de se reconhecer como diferente, como alguém com alguma sorte de deficiência. Afinal, o acesso a bens em condições de igualdade em relação aos demais indivíduos permite uma melhor identificação 
com o meio, e também uma maior participação na esfera pública de tomada de decisões. É por esse motivo, primordial e fundamental, que a Lei n. ${ }^{\circ}$ 13.146, de 6 de julho de 2015, que institui no Brasil o Estatuto da Pessoa com Deficiência, chama-se "Lei Brasileira de Inclusão da Pessoa com Deficiência (Estatuto da Pessoa com Deficiência)".

Grifou-se a palavra "inclusão" pelo fato de consistir em palavra chave no modelo social preconizado pela novel legislação, em favor não só das pessoas com deficiência, como também de toda a comunidade política brasileira. Do ponto de vista político-social, inclusão expressa a exigência de acolhimento de todos os interessados em um processo público de construção de decisões políticas ${ }^{23}$.

Ao lado da ideia de inclusão, caminha a ideia de reconhecimento. O reconhecimento de um indivíduo em sua comunidade política pode ocorrer em dois planos: o primeiro, no plano do indivíduo consigo mesmo. O segundo, no plano do indivíduo em suas relações com os demais. De fato, porque o homem associa-se por natureza (é um animal político), é nesse espaço de interação intersubjetiva que poderá desenvolver-se em sua individualidade. Do contrário, teria limitado o desenvolvimento de sua capacidade de comunicação, cognição, e também de seus sentimentos (amor, ódio, ambições). É na interação com o outro e no contato com a diferença que o homem encontra e constrói a sua identidade. Eis o reconhecimento em um primeiro plano (conhecer sua identidade por se reconhecer na diferença).

Em um segundo plano, o reconhecimento opera em relação não a si próprio, mas em relação aos demais indivíduos (família, amigos, trabalho, comunidade, sociedade). Aqui, a inclusão age em reciprocidade com o reconhecimento. $\mathrm{O}$ indivíduo que se reconhece em sua individualidade com relação aos demais, e, reversamente, é por

23 As considerações ora apresentadas no que diz respeito às ideias de inclusão e reconhecimento foram trabalhadas, com ligeiras modificações, na tese Atividade política judicial - elementos conceituais, da autoria de Ana Lucia Pretto Pereira, no prelo pela Editora Arraes. 
estes reconhecido, sente-se e acha-se de fato (desde a perspectiva dos demais) incluído. Assim como o Estatuto da Pessoa com Deficiência, as políticas públicas que fixam cotas para grupos sub-representados na sociedade são um bom exemplo: inclusão e reconhecimento de indivíduos em múltiplos espaços sociais ${ }^{24}$.

Eis, portanto, a dimensão social do Estatuto da Pessoa com Deficiência: inclusão do indivíduo com deficiência, para que possa se reconhecer como pertencente a uma comunidade política que integra e constitui.

\section{Paternalismo e o Estatuto da Pessoa com Deficiência (Lei n. $\left.{ }^{\circ} 13.146 / 15\right)$}

Pelo regime paternalista, todos podem vir a sofrer intervenção sobre sua liberdade enquanto meio imprescindível para conservação de seu próprio bem-estar. Nesse caso, o sujeito para o qual se dirige a intervenção restará identificado a partir de sua particular vulnerabilidade perante determinada(s) situação(ões) fática(s). Como consequência, será este o indivíduo que, porque desprovido de sua plena autonomia, por qualquer razão, deverá gozar da proteção normativa de acordo com o paternalismo jurídico.

Em regra, a legitimidade do comportamento paternalista nem sempre estará presumida, devendo ser reconhecida a partir da "condição do sujeito" e dos riscos criados pelo seu comportamento. As condições objetivas para que um indivíduo possa ser considerado passível de especial proteção estatal foram recentemente remodeladas no Código Civil por força das alterações legislativas introduzidas pela Lei $n .^{\circ}$

24 Para Axel Honeth, o desenvolvimento das sociedades é resultado da luta por reconhecimento de seus indivíduos em três estágios, todos pautados sob distintas formas de injustiça moral por eles vivenciadas. Esses três estágios seriam: "auto-confiança, que é obtida nas relações afetivas com nossos entes queridos; auto-respeito, nas relações juridicamente institucionalizadas; e autoestima, decorrente de nossas contribuições singulares reconhecidas pela comunidade a que pertencemos." (BUNCHAFT, 2009, p. 378). 
13.146/2015, conhecida como Estatuto da Pessoa com Deficiência ${ }^{25}$. De acordo com o referido Estatuto, são reconhecidamente incapazes para o exercício dos atos da vida civil apenas os indivíduos menores de 16 anos de idade ${ }^{26}$.

Em razão do Estatuto da Pessoa com Deficiência ter retirado da condição de absolutamente incapaz a pessoa com deficiência (ao revogar os incisos I, II e III do art. $3^{\circ}$ do Código Civil), reconhecendo sua plena capacidade civil, questiona-se: estaria a pessoa com deficiência sendo desprotegida a partir do momento em que o Estado deixa de reconhecê-la como absolutamente incapaz?

Para que se possa responder à pergunta, é importante primeiramente fazer uma observação. A autonomia não está centrada apenas na ideia de bem-estar dos indivíduos. Inclui também a noção de integridade, no sentido de potencialidade para exercer a tomada de decisões (MENEZES, 2015, p. 11). O Estatuto da Pessoa com Deficiência trouxe uma importante inovação no que diz respeito à tomada de decisões pelas pessoas com deficiência: trata-se de divisar, para fins de curatela, as questões de natureza patrimonial das questões de natureza existencial. O Estatuto prevê, à pessoa com deficiência, liberdade para decidir como julgar mais adequado para si, e não incidência de curatela. Eis, aqui, uma dimensão importante da ideia de autonomia. O tema será retomado logo adiante.

Nesse ponto, surge novamente a pergunta: o Estado estaria deixando de cumprir com seu papel paternalista, no sentido de prover indivíduos em condição de vulnerabilidade de ferramentas que lhes

25 O Estatuto da Pessoa com Deficiência vem consolidar o compromisso do Estado brasileiro com a inclusão de grupos minoritários ou subrepresentados, compromisso esse firmado no cenário internacional por meio da Convenção sobre Direitos das Pessoas com Deficiência, incorporada na ordem jurídica interna pelo Decreto Legislativo n. ${ }^{\circ}$ 186/2008 e promulgada pelo Decreto Presidencial $n .^{\circ} 6.949 / 2009$.

26 A Lei n. ${ }^{\circ} 13.146 / 2015$ excluiu do rol de absolutamente incapazes "os que, por enfermidade ou deficiência mental, não tiverem o necessário discernimento para a prática desses atos"; e também "os que, mesmo por causa transitória, não puderem exprimir sua vontade". Eis a nova redação do art. $3 .^{\circ}$ do Código Civil: "Art. $3^{\circ}$. São absolutamente incapazes de exercer pessoalmente os atos da vida civil os menores de 16 (dezesseis) anos." 
permitam melhor viver, e tomar decisões adequadas, ao atribuir, às pessoas com deficiência, a possibilidade de decidirem sobre questões de ordem eminentemente existencial?

Reconhecer o indivíduo com deficiência enquanto capaz para a tomada de decisões sobre questões de ordem existencial pressupõe reconhecer-lhe, antes, como pessoa dotada de certa dose de autonomia. Ao compreender a autonomia enquanto transcendente à ideia de bemestar é possível nela incluir uma dimensão que leva em consideração elementos subjetivos, que impulsionam a vontade individual. A vontade individual será exteriorizada por intermédio da expressão; em outras palavras, haverá manifestação de vontade desde que esta possa, por meios os mais variados possíveis, ser expressa. Vontade de viver, de participar, de interagir são exemplos.

Portanto, a partir do momento em que o Estado reconhece, ainda que parcialmente, a autonomia dos indivíduos com deficiência, não parece estar a deixar de protegê-los. Afinal, prevê na própria lei (Estatuto) instrumentos por meio dos quais essa autonomia poderá ser exercida sem prejuízo da sua condição de vulnerabilidade (como é o caso, por exemplo, da curatela e da tomada de decisão apoiada). A atitude estatal paternalista consiste em retirar uma parte da autonomia dos indivíduos com deficiência para que justamente uma outra parcialidade dessa mesma autonomia possa ser exercida, notadamente por meio da possibilidade de serem tomadas decisões sobre questões de ordem existencial. Há aqui possibilidade de expressão de vontade da pessoa com deficiência.

É importante observar, nesse ponto, que as escolhas a serem feitas pela pessoa com deficiência no campo existencial, porque carregadas de subjetividade, podem não corresponder a uma vontade objetivamente considerada. Logo, ainda que essas escolhas sejam ou não as melhores para os padrões socialmente eleitos para uma vida física, psíquica ou economicamente saudável, não importa: o exercício da autonomia atrela-se a uma condição capacitatória do agente, ainda 
que não esteja em consonância com aquilo que a sociedade acolha ou esteja permitindo reconhecer como padrão.

De acordo com a Lei $n .^{\circ} 13.146 / 15$, a curatela da pessoa com deficiência estaria restrita apenas às questões de ordem patrimonial e negocial. Nada obstante, a legítima intervenção na autonomia de qualquer indivíduo necessariamente dependerá da concreta aferição, caso a caso, do grau de discernimento do sujeito (MENEZES, 2015, p. 12). A autonomia do indivíduo com deficiência não deixará de ser resguardada, haja vista que referida pessoa não deixa de ser titular dos direitos da personalidade e por eles ter assegurada sua dignidade (MENEZES, 2014, p. 63).

Nesse diapasão, o Estatuto, em seu artigo $6^{\circ}$, prevê expressamente que a deficiência não afeta a plena capacidade civil da pessoa para os atos de sua esfera existencial, tais como casar-se, exercer a adoção, dentre outros direitos. A medida concretiza a promoção da autonomia desses indivíduos os apartando de uma intervenção totalmente paternalista por parte do Estado.

A previsão legislativa em questão vem atender ao que a Convenção da Pessoa com Deficiência pareceu adotar por meio da teoria da incindibilidade, "entre titularidade do direito e capacidade de exercício quando aborda as situações subjetivas existenciais". (MENEZES, 2014, p. 68-69). Pelas próprias características definidoras dos direitos da personalidade - intransmissibilidade, irrenunciabilidade e indisponibilidade -, não se concebe que haja o exercício desses direitos senão por seu próprio titular.

Porém, na hipótese de o sujeito se encontrar em dificuldades que comprometam sua capacidade legal para o estabelecimento de escolhas que venham impactar de modo maior ou menor em sua dignidade humana, poderão ser aplicados os processos legalmente previstos de tomada de decisão apoiada ou, em caráter de excepcionalidade, de curatela (excluída a tomada de decisões de ordem existencial, como observado). 
Prevista na Lei $13.146 / 15$, art. 84 , $\S 2^{\circ}$ e art. 116 , este último responsável pela inserção do art. 1.783-A ao Código Civil, a tomada de decisão apoiada consiste em um processo que efetivamente servirá em prol da pessoa com deficiência como instrumento apto a lhe conferir segurança ao prover respaldo fundamentador para embasar sua decisão quando do exercício de sua capacidade.

A tomada de decisão apoiada surge como uma "ajuda a que a pessoa com alguma limitação mantenha a sua autonomia mas, visando cercar-se de maior proteção, possa receber apoio de terceiros no processo de tomada de decisão, sobretudo aquelas que implicarem efeitos jurídicos para si e/ou terceiros" (MENEZES, 2015, p. 13). Tal processo será impulsionado por pedido da própria pessoa com deficiência, perante instância judicial estadual de primeiro grau, mediante a indicação de pelo menos 2 (duas) pessoas idôneas com as quais possua aproximação e que gozem de sua confiança para expressar o que lhe pareça ser mais adequado sobre quaisquer atos de sua vida civil (patrimoniais ou extrapatrimoniais). Os sujeitos definidos como apoiadores assumem específica responsabilidade para que, por uma proba conduta, forneçam aconselhamento por elementos e informações necessárias, que garantirão ao solicitante a manutenção de sua autonomia pelo exercício do seu direito de decisão.

Pelo magistério do Carlos Pianovski Ruzyk (2015), ao adotar o instituto da tomada de decisão apoiada, a Lei n. ${ }^{0} 13.146 / 2015$ atuou em consonância com o art. 12 da Convenção sobre os Direitos da Pessoa com Deficiência ${ }^{27}$, porém, inevitavelmente, implicou na mudança das compreensões que até então se aplicavam ao direito privado para impor a transmutação do paradigma paternalista para o de empoderamento.

Já no que diz respeito à curatela, permanece o instituto como instrumento de restrição para exercício dos atos da vida civil, mas,

27 A Convenção sobre os Direitos da Pessoa com Deficiência proposta pela Organização das Nações Unidas foi ratificada no Brasil pelo Decreto $n^{\circ} 186 / 2008$, que nos termos do art. $5^{\circ}, \S 3^{\circ}$, da Constituição Federal, recebeu a hierarquia de Emenda Constitucional. 
pelo caráter extremado atribuído a tal medida, deverá (após o devido processo legal certificador de sua premente necessidade) ser restringida aos limites demandados especificamente e por duração estritamente necessária (art. 84, Lei n. $\left.{ }^{\circ} 13.146 / 2015\right)$.

Assim, o instituto da curatela assume nova roupagem em consonância com a própria Convenção sobre os Direitos da Pessoa com Deficiência ao passar a albergar um "formato de curatela mais humanizado" pela atribuição de "maior relevo às circunstâncias pessoais do próprio curatelado" (MENEZES, 2015, p. 15). Porém, pelo próprio caráter protetivo que referido instituto possui, o mesmo não deixa de existir pela proteção e segurança daqueles que demandarem referida interferência paternalista do Estado.

Cabe, por fim, uma importante consideração. Conforme expressa disposição legal (art. 85, Lei n. ${ }^{1}$ 13.146/2015), como anteriormente observado, a curatela afetará tão somente os atos patrimoniais, não sendo extensiva aos direitos existenciais sobre o próprio corpo, sexualidade, matrimônio, privacidade, educação, saúde, trabalho e voto.

Até aqui, duas diferenças podem ser expostas se comparadas ao mecanismo da tomada de decisão. Verifica-se, de acordo com o Estatuto, que, enquanto o objeto da curatela são os direitos de natureza patrimonial, na tomada de decisão o objeto se amplia para admissão de quaisquer atos da vida civil, patrimoniais ou não. Segundo, ao tempo em que nos atos patrimoniais a atuação do conselheiro, na tomada de decisão, circunda-se apenas e tão somente a direcionamentos; na curatela, o curador passa a ter poderes para atuar efetivamente de acordo com os interesses da pessoa com deficiência.

Assim, surge outra pergunta: uma vez que o Estatuto da Pessoa com Deficiência expressamente restringe o uso da curatela à tomada de decisão sobre questões de ordem patrimonial, como poderiam, as pessoas com deficiência, ser assistidas ou representadas no caso de questões de ordem existencial? (MENEZES, 2015, p. 17). Observa-se que o Estatuto não se refere à representação ou à assistência desses sujeitos para os atos não patrimoniais, o que levaria à conclusão de 
sua desproteção, o que, por sua vez, leva a se criar considerações que, conforme Carlos Pianoviski Ruzyk (2015), o estatuto deveria ter adotado uma postura menos radical, no sentido de não determinar a incompatibilidade da curatela para os âmbitos das relações existenciais.

Percalços à parte, resta atribuído ao magistrado (art. $84, \S 3^{\circ}$ da Lei n. $\left.{ }^{\circ} 13.146 / 2015\right)$ o dever de delinear medidas de proteção proporcionais às necessidades e às circunstâncias de cada caso, de modo que melhor atendam ao curatelado através da imposição de deveres ao curador que, preferencialmente, deverá ser sujeito que possua vínculo de natureza familiar, afetiva ou comunitária com o curatelado.

Da omissão legislativa compreende-se que, em determinadas questões existenciais, de fato, não se recomenda intervenção do curador (como o caso do exercício do direito de voto ou sua anuência para o casamento). Todavia, para as hipóteses cujas incongruências legais comprometam a proteção do indivíduo em sua seara existencial (como para determinada situação que exija uma intervenção médica), parece que somente o paternalismo judicial conseguirá trazer concretude ao princípio da dignidade da pessoa humana.

A fixação dos limites da curatela deve evitar dois extremos: de um lado, a proteção excessiva que aniquila toda autonomia da pessoa, lançando-a em um estado semelhante ao da morte civil. De outro lado, a limitação da curatela apenas à administração do patrimônio, excluindo, em abstrato e a priori, eventual e necessária proteção no plano das questões existenciais. Se houver necessidade de proteger o interdito no âmbito dessas questões não patrimoniais, a curatela deverá recair também sobre tais interesses, respeitadas as salvaguardas importantes à efetivação dos direitos humanos. (MENEZES, 2015, p.18).

Por essa razão, o paternalismo estatal se justifica a partir do reconhecimento da incapacidade de qualquer ser humano, como 
mecanismo apto a proporcionar a superação deste déficit, criado por singularidades próprias, que venha a tornar-lhe vulnerável para a prática dos atos fundamentais à sua própria vida.

E, dentro desse contexto, o Estatuto da Pessoa com Deficiência é responsável por promover a devida "emancipação" da pessoa com deficiência para o âmbito dos padrões legais e sociais quando impõe, por primazia, a necessidade de se reconhecer e respeitar a autonomia inerente a esses indivíduos.

Nas situações em que a pessoa com deficiência seja totalmente desprovida de discernimento ou possua graves comprometimentos para gerir sua própria vida - patrimonial ou extrapatrimonial -, resgata o Estado seu papel paternalista obrigatório ao trazer pelo paternalismo jurídico (através do instituto da curatela), ou pelo paternalismo judicial (pela atuação do magistrado), a medida necessária de proteção pessoal ao indivíduo pelo zelo a seus direitos humanos e fundamentais.

Outras dúvidas e críticas começam a surgir de forma volumosa sobre os conceitos jurídicos trabalhados pelo Estatuto e, principalmente, sobre outras alterações trazidas pela Lei n. ${ }^{\circ} 13.146 / 2015$ ao ordenamento brasileiro em geral. Questionamentos acerca da efetiva proteção que o referido diploma pode trazer à pessoa com deficiência serão crescentemente levantados. De qualquer modo, é importante reconhecer que as respectivas respostas somente poderão ser referendadas pela experiência, e pelo decurso do tempo.

\section{Conclusão}

Pode-se concluir que o caminho que leva ao atendimento da dignidade da pessoa humana também passa pelo princípio da isonomia à medida que, identificando as singularidades existentes em cada indivíduo (no caso, na pessoa com deficiência), impõe-se o cumprimento de medidas que amparem vulnerabilidades de forma não violadora à sua autonomia enquanto sujeito de direito. Nesse ponto, importante lembrar Marcos Maliska (2015), segundo quem é preciso ter o cuidado 
de distinguir a intervenção para "promover" a autonomia da intervenção para "impedir" a autonomia (MALISKA, 2015).

Conclui-se, portanto, que o Estatuto da Pessoa com Deficiência, ao promover inovações legislativas que retiram a pessoa com deficiência do rol de incapazes do Código Civil, tem como objetivo, em princípio, reconhecer a pessoa com deficiência como igual para a tomada de decisões de seu interesse, sobretudo aquelas de ordem existencial. $O$ paternalismo estatal encontra-se presente por via da curatela e da tomada de decisão apoiada, afastando-se, porém, única e exclusivamente, no caso da tomada de decisões de ordem existencial.

Nada obstante, é importante lembrar que para esse núcleo de direitos, o legislador excluiu tão somente a curatela, omitindo-se quanto à possibilidade da tomada de decisão apoiada. Sendo assim, tem-se que o Estatuto da Pessoa com Deficiência, desde uma perspectiva estritamente normativa (a experiência firmará, ou não, a novel legislação), ajusta-se às demandas de inclusão social das pessoas com deficiência, considerando-as prescritivamente em condições de igualdade, porém ressalvando os cuidados necessários em face da condição de vulnerabilidade em que tais indivíduos possam vir a se encontrar.

\section{Referências}

ALEMANY, Macario. Breve nota sobre la idea de "paternalismo" em la obra de Ernesto Garzón Valdés. Doxa, Alicante, n. 30, p. 35-38. 2007. Disponível em: < http://rua.ua.es/dspace/bitstream/.../1/DOXA_30_04. pdf>. Acesso em: 02 fev. 16.

ALEMANY, Macario. El concepto e justificacion del paternalismo. Doxa - Cuadernos de Filosofia del Derrecho, Alicante, n. 28, p. 265-303. 2005. Disponível em: <http://rua.ua.es/dspace/handle/10045/10012>. Acesso em: 19 jan. 16. 
BONAVIDES, Paulo. Do Estado Liberal ao Estado Social. 11.ed. São Paulo: Malheiros, 2013.

BUNCHAFT, Maria Eugênia. A Filosofia Política do Reconhecimento. In: SARMENTO, Daniel (Coord.). Filosofia e Teoria Constitucional Contemporânea. Rio de Janeiro: Lumen Juris, 2009.

BRASIL. Lei n 13.146, de 06 jul. 2015. Institui a Lei Brasileira de Inclusão da Pessoa com Deficiência (Estatuto da Pessoa com Deficiência). Disponível em: < http://www.planalto.gov.br/ccivil_03/_ Ato2015-2018/2015/Lei/L13146.htm>. Acesso em: 02 fev. 2016.

CABRAL, Érico de Pina. A "autonomia" no direito privado. Revista de Direito Privado, n. 9. São Paulo: Revista dos Tribunais. jul./set. 2004.

CALDAS, Ana Ferraz. Paternalismo Jurídico: da proteção à intromissão (conceito, legitimidade e limite das medidas paternalistas). 2012. 76f. Dissertação (Mestrado em Ciências Jurídico-Filosóficas)

- Faculdade de Direito da Universidade do Porto, Porto, 2012.

Disponível em: <https://repositorio-aberto.up.pt/handle/10216/66148>. Acesso em: 20 jan. 2016.

CARVALHO, Kildare Gonçalves. Direito constitucional: Teoria do Estado e da Constituição. Direito constitucional positivo. 14. ed. Belo Horizonte: Del Rey, 2008.

DALLARI, Dalmo de Abreu. Elementos de Teoria Geral do Estado. 31. ed. São Paulo: Saraiva, 2012.

DWORKIN, Gerald. Paternalism - Morality and the law. EUA:

Wadsworth, 1971. p. 181-188. Disponível em: <http://www.sjsu.edu/ people/paul.bashaw/courses/phil186fall2012/s1/Paternalism.pdf>. Acesso em: 18 jan. 2016.

FARIAS, Cristiano Chaves de.; ROSENVALD, Nelson. Direito das Obrigações. 5. ed. Rio de Janeiro: Lumen Juris, 2011.

FERREIRA, Aurélio Buarque de Holanda. Mini Aurélio: o dicionário da língua portuguesa. 8. ed. Curitiba: Positivo, 2010.

KIRSTE, Stephan. Autonomia e direito à autolesão. Para uma crítica do paternalismo. Revista de Direitos Fundamentais e Democracia, Curitiba, v. 14, p. 73-86, jul./dez. 2013. 
MALISKA, Marcus Augusto. Curitiba: Unibrasil Centro Universitário, 05 nov. 2015. Aula ministrada no Programa de Pós-Graduação Mestrado em Direitos Fundamentais e Democracia.

MARTINELLI, João Paulo Orsini. Paternalismo Jurídico-penal. 2010. 297f. Tese (Doutorado em Direito) - Universidade de São Paulo, São Paulo. 2010. Disponível em: <http://www.teses.usp.br/teses/ disponiveis/2/2136/tde.../TESE_versao_final.pdf.>. Acesso em: 18 jan. 2016.

MENEZES, Aderson de. Teoria geral do Estado. 8.ed. Rio de Janeiro: Forense, 1998.

MENEZES, Joyceane Bezerra de. A capacidade dos incapazes: o diálogo entre a convenção da ONU sobre os direitos das pessoas com deficiência e o Código Civil Brasileiro. In: RUZYK, Carlos Eduardo Pianovski; SOUZA, Eduardo Nunes de; MENEZES, Joyceane Bezerra; EHRHARDT JUNIOR, Marcos (Org.). Direito Civil Constitucional - A ressignificação da função dos institutos fundamentais do direitocivil contemporâneo e suas consequências. Florianópolis: Conceito Editorial, 2014. p. 51-74.

MENEZES, Joyceane Bezerra de. O direito protetivo no Brasil após a Convenção sobre a Proteção da Pessoa com Deficiência: impactos do novo CPC e do Estatuto da Pessoa com Deficiência. Civilistica.com., Rio de Janeiro, n. 1, 2015. Disponível em: <http://www. civilistica.com/ o-direito-protetivo-no-brasil>. Acesso em: 06 fev. 2016.

NOVAIS, Jorge Reis. Contributo para uma teoria do estado de direito: Do estado de direito liberal ao estado social e democrático de Direito. Coimbra: Editora Coimbra, 1987.

PINHEIRO, Rosalice Fidalgo. Princípio da boa-fé nos contratos: o percurso teórico e sua recepção no direito brasileiro. Curitiba: Juruá, 2015.

PINHEIRO, Rosalice Fidalgo. Contrato e direitos fundamentais. Curitiba: Juruá, 2009.

PINHEIRO, Rosalice Fidalgo. $\mathbf{O}$ abuso do direito e as relações contratuais. Rio de Janeiro: Renovar, 2002. 
RAMIRO AVILÉS, Miguel A. A vueltas com el paternalismo jurídico. Derechos y libertades, Madri (Espanha), n 15, p.211-256, jun. 2006. Disponível em: <http://www.e-archivo.uc3m.es/.../DyL-2006-15-Ramiro. pdf?...1> Acesso em: 19 jan. 2016.

ROHRMANN, Carlos Alberto; RÊGO, Cristiane. O paternalismo e o fenômeno da juridicização da vida privada. Revista da Faculdade de Direito Milton Campos. v. 27, p. 119-140, 2013. Disponível em: <http://ojs.mcampos.br/index.php/RFDMC/article/view/34>. Acesso em 02 fev. 2016.

RUZYK, Carlos Eduardo Pianovski. Palestra proferida no V Congresso de Direito Empresarial e Cidadania da Unicuritiba (Centro Universitário Curitiba). Curitiba - PR, em 20 out. 2015.

SARMENTO, Daniel. Direitos fundamentais e relações privadas. 2. ed. Rio de Janeiro: Lumen Juris, 2006.

SCHIER, Adriana da Costa Ricardo. A participação popular na administração pública: o direito de reclamação. Rio de Janeiro: Renovar, 2002.

TEIXEIRA, Ana Carolina Brochado. Saúde, corpo e autonomia Privada. Rio de Janeiro: Renovar, 2010.

VALDÉS, Ernesto Garzón. Es eticamente justificable el paternalismo jurídico? Doxa, Alicante, n. 5, p. 155-173. 1988. Disponível em: <http:// rua.ua.es/dspace/handle/10045/10872>. Acesso em: 02 fev. 2016.

Recebido em: 14/06/2016

Aprovado em: 25/08/2016 